\section{Room-Temperature Storage of Coconut Pollen}

Pollen introduction and exchange have been suggested as a means of broadening the scope of breeding programmes designed to produce diseaseresistant and high-yielding coconuts ${ }^{1-3}$; and at a recent meeting of the Food and Agriculture Organization Technical Working Party on Coconut Production it was stressed ${ }^{4}$ that the most important material question to be solved concerned the mode of transportation of pollen. It is clear that present methods of storage of coconut pollen ${ }^{5-8}$, though useful, are inconvenient for routine pollen exchanges over long distances.

J. R. King ${ }^{9-11}$ has reported prolonged roomtemperature storage of freeze-dried pollens in sealed containers under an inert gas, and more recently under vacuum ${ }^{12}$; and early results of work on storage and dispatch initiated in this Department show that coconut pollen similarly treated can be stored for long periods at room temperature.

In one experiment, unopened male flowers from inflorescences of six 'Jamaica tall' palms $(A-F)$ were placed in separate newspaper envelopes and ovendried at $40^{\circ} \mathrm{C}$ (for approximately 2 days). Pretreatment in this way has resulted in greatly increased quantities of pollen ${ }^{13}$. Initial pollen viability estimates were made from counts of at least 400 grains after germination on a sucrose gelatine medium (10 per cent sucrose, 10 per cent gelatine).

The equipment used for freeze drying consisted of a 6-port ampoule header connected by a U-tube to a high-vacuum pump. Ampoules containing pollen were attached and pre-frozen by immersion in dry ice and acetone before drying under vacuum $(2-5 \mathrm{~mm}$ mercury). The U-tube surrounded by freezing mixture served as a moisture trap.

Duplicate batches of 6 ampoules after $3 \mathrm{~h}$ freeze drying were heat-sealed under vacuum.

After one month's storage at room temperature, samples $A_{1}, B_{1}$ and $C_{1}$ were opened and viabilities estimated immediately, after 2 and $4 \mathrm{~h}$, and after one day at relative humidity 70 per cent. Samples from $D_{1}, E_{1}$ and $F_{1}$ were similarly tested after two months and replicates $D_{2}, E_{2}$ and $F_{2}$ were then packed in light-weight polystyrene containers and separately dispatched on a round trip to New Guinea. Viability was again tested in vitro, approximately 4 months after collection. The results obtained are given in Table 1.

The results show that freezo drying is a workable technique for the treatment of coconut pollen, since viability obtained after prolonged room temperature storage is in excess of that normally required for pollination. Further samples $A_{2}, B_{2}$ and $C_{2}$ still

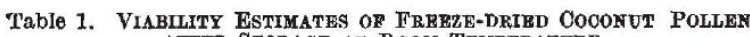
AFTER STORAGE AT ROOM TEMPBRATURE

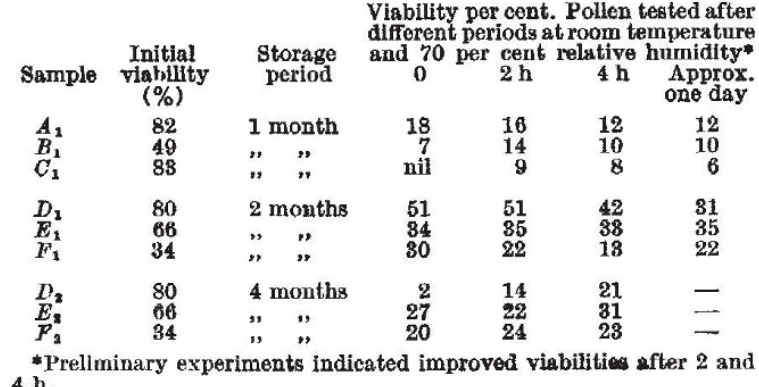

remain to be tested at 6 months, and the results of $a$ number of controlled pollinations and further experiments to determine the optimum period of freeze drying will be reported later.

The ability to store coconut pollen for prolonged periods at room temperature will be an asset to coconut breeding and seed production, and, in particular, will facilitate introduction and exchange.

I thank Dr. J. L. Plimmer, of the University College of the West Indies, for help with the freeze-drying technique. Thanks are also due to Mr. T. A. Jones, director of this Department, for advice, to Mr. A. E. Charles of the Department of Agriculture, Keravat, New Britain, in the Territory of Papua and New Guinea, who co-operated by labelling and returning the samples, and to Mrs. M. Hall for technical assistance with the pollen viability tests.

Coconut Industry Board,

R. A. Whitehead

Research Department, P.O. Box 204,

Kingston 10, Jamaica, W.I.

${ }^{1}$ MoWhorter, F. P., Araneta J. Agric., 6, 13 (1059).

3 Barrau, J., Symp., Tropical Crops Improvement with Particular fieference to the Coconut Palm. Tenth Pacific Sci. Cong., Hono-
lulu, Hawail (1961).

3 Charles, A. R., Trop. Agric. (Trin.), 88, 288 (1961).

- Ziller, R.. Meeting of W.A.O. Technical Working Party on Coconut Production, Trivandrum, South India (Nov. 1961).

- Manthiriratne, M. A. P. P., and Liyanage, D. V., Ceylon Coconut Planters Rev., 1, 1 (1960).

- Liyanage, D. V., Ceylon Cocon. Quart., 5, No. 3, 135 (1054).

'Liyanage, D. V., Ann. Rep. Cocon. Res. Bd. Cocon. Res. Inst. for 1957 : Sessional Paper VIII (1959).

B.R.H.0.-Instructions Générales Fécondations Artificielles (1961).

- King, J. R., Bull. Torr. Bot. Club, 86, 383 (1959).

${ }^{10}$ King, J, R., Amer. Fruit Gr., 80, 51 (1960).

${ }^{11}$ King, J. R., Econ. Bot., 15, 91 (1961).

1" King, J. R. (private communieation).

${ }^{13}$ Res. Dept. Cocon. Ind. Bd. Jamaicd, Ann. Rep. (in preparation).

\section{A Technique for inoculating Wheat with Rusts for Glass-house and Test-tube Culture}

The conventional method of inoculating wheat with rusts is to plant wheat seed in pots in a glasshouse and smear the first leaf with spores of rust when the seodlings are 6-7 days old. The pots are incubated for $24 \mathrm{~h}$ in a moist chamber and then transferred to the benches of the glass-house. This technique takes about 15-20 days from the date of seeding to the date of the appearance of the rusts, depending on the species of the rust, temperature and light conditions in the glass-house being favourable for the development of the different species of the rusts.

For inoculating wheat with rusts by this technique for glass-house and test-tube culture, wheat seeds are germinated in a Petri plate on a moist filter paper in a room. After $60-72 \mathrm{~h}$, when the plumule has grown about half an inch, the seed is picked up by hand. Meanwhile, a spore suspension of rust is made in sterile water containing a trace of detergent. Using a fine needle in a hypodermic syringe, the spore suspension is injected a little above the point from where the plumule and radical are differentiating. The test of successful inoculation is the appearance of a drop or the ejection of a fine squirt of water from the tip of the plumule. If this drop is taken on a slide and examined under the mioroscope, it will be found to contain the rust spores. With a little practice, it is possible to inoculate about 